Case Reports
in Dermatology
Case Rep Dermatol 2021;13:190-194

DOI: 10.1159/000513938

Published online: April 1, 2021
(C) 2021 The Author(s)

Published by S. Karger AG, Basel www.karger.com/cde

\title{
Topical Tofacitinib: A Janus Kinase Inhibitor for the Treatment of Vitiligo in an Adolescent Patient
}

\author{
Sineida Berbert Ferreira ${ }^{a, b} \quad$ Rachel Berbert Ferreira ${ }^{b, c}$ \\ Afonso Cesar Neves Neto ${ }^{c}$ Silvana Martins Caparroz Assef ${ }^{b}$ \\ Morton Scheinberg ${ }^{\text {d, e }}$ \\ aPrivate Dermatologic Clinic, Maringá, Brazil; ${ }^{b}$ CEPED - Centro Paranaense de Estudos em \\ Dermatologia, Maringá, Brazil; 'UNICESUMAR - Centro Universitario de Maringá, \\ Maringá, Brazil; dHospital Israelita Albert Einstein - Rheumatology and Orthopedic

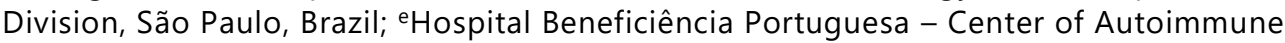 \\ Disease, São Paulo, Brazil
}

\section{Keywords}

Tofacitinib · Vitiligo · Janus kinase inhibitor · JAK inhibitor - Topical tofacitinib · Phototherapy . Treatment $\cdot$ Adolescent

\begin{abstract}
Vitiligo is an autoimmune skin disease presenting with areas of depigmentation. Recent reports suggest that Janus kinase (JAK) inhibitors may be an effective therapy. In this case report, we show our experience with an adolescent patient with a long history of generalized and refractory vitiligo, for which treatment with topical tofacitinib, a JAK inhibitor, associated with phototherapy for 9 months, resulted in near complete repigmentation.
\end{abstract}

(C) 2021 The Author(s)

Published by S. Karger AG, Basel

\section{Introduction}

Vitiligo is a chronic autoimmune disease characterized by the progressive disappearance of melanocytes, causing depigmentation. The standard treatment includes topical and

\begin{tabular}{ll}
\hline & Sineida Berbert Ferreira \\
& Rua Vereador Nelson Abrão \\
& 2005, zona 5 \\
Maringá, Paraná (Brazil) \\
sineidaferreira@yahoo.com.br
\end{tabular}




\section{Case Reports in Dermatology}

Case Rep Dermatol 2021;13:190-194

DOI: $10.1159 / 000513938$

C 2021 The Author(s). Published by S. Karger AG, Basel www.karger.com/cde

Berbert Ferreira et al.: Topical Tofacitinib for the Treatment of Vitiligo in an Adolescent

systemic corticosteroids, topical calcineurin inhibitors, psoralens, and phototherapy (narrowband [NB]-UVB and UVA combined with psoralen); however, none of those treatments are reliably effective [1]. Recent reports and studies have shown benefits from both oral and topical Janus kinase (JAK) inhibitors in adults with vitiligo [2-4].

\section{Case Report}

We report on the case of a 17-year-old boy with stable nonsegmental vitiligo with acrofacial involvement (Fig. 1) with a 15-year evolution. He had no other clinical or autoimmune condition and denied any family history of vitiligo. Previous treatments included oral corticosteroids for 4 years, alternating 6 months each because of unstable vitiligo, antioxidants, and oral vitamin D, topical tacrolimus for 6 months, and topical corticosteroids for another 6 months.

He had done 1 year of phototherapy (NB-UVB) with no improvement at all, as well as NBUVB associated with topical corticosteroids and topical tacrolimus during 3 years, with little improvement. As previous reports have suggested [2], light exposure in patients using JAK inhibitors as a therapy for vitiligo may improve repigmentation; thus, considering the high cost of the treatment, the patient already started on a combined therapy: topical tofacitinib $2 \%$ + vehicle (ointment) (Chemistry Rx Compounding and Specialty Pharmacy, Folcroft, PA, USA) twice daily only on the facial lesions, combined with NB-UVB phototherapy, 3 times a week, during 9 months. The total dose for the face vitiligo was $1,000 \mathrm{~mJ} / \mathrm{cm}^{2}$, starting with $200 \mathrm{~mJ} / \mathrm{cm}^{2}$ and increasing by $50 \mathrm{~mJ} / \mathrm{cm}^{2}$ each session.

Before he started on topical tofacitinib, the patient underwent a baseline laboratory evaluation. During treatment, he repeated the tests, which revealed no abnormalities. A complete review of his systems was negative. After 9 months of therapy, significant repigmentation of the forehead, nose, eyes, and lips was observed (Fig. 2). He had minor adverse events such as erythema and transient acne.

\section{Discussion}

A new hypothesis about the pathogenesis of vitiligo suggests that both genetic and nongenetic factors interfere in melanocytes, resulting in their immune-mediated destruction [5]. Recent studies have shown that in the pathogenesis of vitiligo, CD8+ T cells and interferon- $\gamma$ play key roles in the destruction of melanocytes [6].

Tofacitinib is a JAK inhibitor approved by the US Food and Drug Administration in 2012 and by ANVISA (National Agency of Sanitary Vigilance in Brazil) for the treatment of rheumatoid arthritis and psoriatic arthritis. Tofacitinib is a JAK1 and JAK3 inhibitor that interferes with interferon- $\gamma$ signaling, which reduces CXCL10 chemokine expression, blocking the activity of vitiligo. The first case suggesting this possible mechanism of action of JAK inhibition was published by Craiglow and King [3]. The success and safety of both oral and topical tofacitinib were shown for the treatment of alopecia areata, including in adolescents [7, 8]. Additional studies and clinical trials of tofacitinib for the treatment of other dermatological and nondermatological conditions are currently underway.

Other case reports on oral and topical JAK inhibitors for vitiligo [2], as well as recently an open-label study with topical $1.5 \%$ ruxolitinib cream, showed good results for facial vitiligo

\section{Karger'}




\section{Case Reports in Dermatology}

\begin{tabular}{l|l}
\hline Case Rep Dermatol 2021;13:190-194 \\
\hline DOI: 10.1159/000513938 & $\begin{array}{l}\text { @ 2021 The Author(s). Published by S. Karger AG, Basel } \\
\text { www.karger.com/cde }\end{array}$ \\
\hline
\end{tabular}

Berbert Ferreira et al.: Topical Tofacitinib for the Treatment of Vitiligo in an Adolescent

[9]. However, there are only limited numbers of case reports for the pediatric and adolescent populations [10]. In our patient, all previous treatments had failed, including systemic corticosteroids, whereas with topical tofacitinib, he experienced considerable facial repigmentation; however, we are aware that longer treatments will probably be necessary for complete repigmentation.

As vitiligo has a remarkable impact on quality of life and can be emotionally devastating, some patients are at higher risk of social discrimination and stigma; therefore, new possibilities of targeted treatments are welcome. This case suggests that topical tofacitinib might be a safe and effective therapy for vitiligo, especially for pediatric and adolescent patients, for whom systemic therapies are not desired. Additional clinical trials will be needed to confirm any real advances and tofacitinib's efficacy in the management of this complex disease.

\section{Statement of Ethics}

Our research was conducted ethically in accordance with the World Medical Association Declaration of Helsinki. Written informed consent was obtained from the patient's parents for publication of this case report and any accompanying images.

\section{Conflict of Interest Statement}

The authors have no conflict of interest to declare.

\section{Funding Sources}

This report has no funding source.

\section{Author Contributions}

S. Berbert Ferreira was responsible for direct management of the patient and was involved in manuscript drafting and the final draft. R. Berbert Ferreira was involved in direct management of the patient and reviewed the pertinent literature and the final draft. A.C. Neves Neto reviewed the pertinent literature and the final draft. S.M.C. Assef reviewed the pertinent literature and the final draft. M. Scheinberg supervised the final draft.

\section{References}

1 Alikhan A, Felsten LM, Daly M, Petronic-Rosic V. Vitiligo: a comprehensive overview Part I. Introduction, epidemiology, quality of life, diagnosis, differential diagnosis, associations, histopathology, etiology, and workup. J Am Acad Dermatol. 2011 Sep;65(3):473-91.

2 Liu LY, Strassner JP, Refat MA, Harris JE, King BA. Repigmentation in vitiligo using the Janus kinase inhibitor tofacitinib may require concomitant light exposure. J Am Acad Dermatol. 2017 Oct;77(4):675-82.e1.

3 Craiglow BG, King BA. Tofacitinib citrate for the treatment of vitiligo: a pathogenesis-directed therapy. JAMA Dermatol. 2015 Oct;151(10):1110-2.

\section{Karger'=}




\section{Case Reports in Dermatology}

\begin{tabular}{l|l}
\hline Case Rep Dermatol 2021;13:190-194 \\
\hline DOI: 10.1159/000513938 & $\begin{array}{l}\text { @ 2021 The Author(s). Published by S. Karger AG, Basel } \\
\text { www.karger.com/cde }\end{array}$ \\
\hline
\end{tabular}

Berbert Ferreira et al.: Topical Tofacitinib for the Treatment of Vitiligo in an Adolescent

4 Harris JE, Rashighi M, Nguyen N, Jabbari A, Ulerio G, Clynes R, et al. Rapid skin repigmentation on oral ruxolitinib in a patient with coexistent vitiligo and alopecia areata (AA). J Am Acad Dermatol. 2016 Feb;74(2):370-1.

5 Spritz RA. Six decades of vitiligo genetics: genome-wide studies provide insights into autoimmune pathogenesis. J Invest Dermatol. 2012 Feb;132(2):268-73.

6 Rashighi M, Harris JE. Interfering with the IFN- $\gamma /$ CXCL10 pathway to develop new targeted treatments for vitiligo. Ann Transl Med. 2015 Dec;3(21):343.

7 Liu LY, King BA. Tofacitinib for the Treatment of Severe Alopecia Areata in Adults and Adolescents. J Investig Dermatol Symp Proc. 2018 Jan;19(1):S18-20.

8 Berbert Ferreira R, Ferreira SB, Scheinberg MA. An excellent response to tofacitinib in a Brazilian adolescent patient with alopecia areata: a case report and a review of the literature. Clin Case Rep. 2019 Nov;7(12):2539-42.

9 Rothstein B, Joshipura D, Saraiya A, Abdat R, Ashkar H, Turkowski Y, et al. Treatment of vitiligo with the topical Janus kinase inhibitor ruxolitinib. J Am Acad Dermatol. 2017 Jun;76(6):1054-60.e1.

10 Olamiju B, Craiglow BG. Tofacitinib cream plus narrowband ultraviolet B phototherapy for segmental vitiligo in a child. Pediatr Dermatol. 2020 Jul;37(4):754-5.
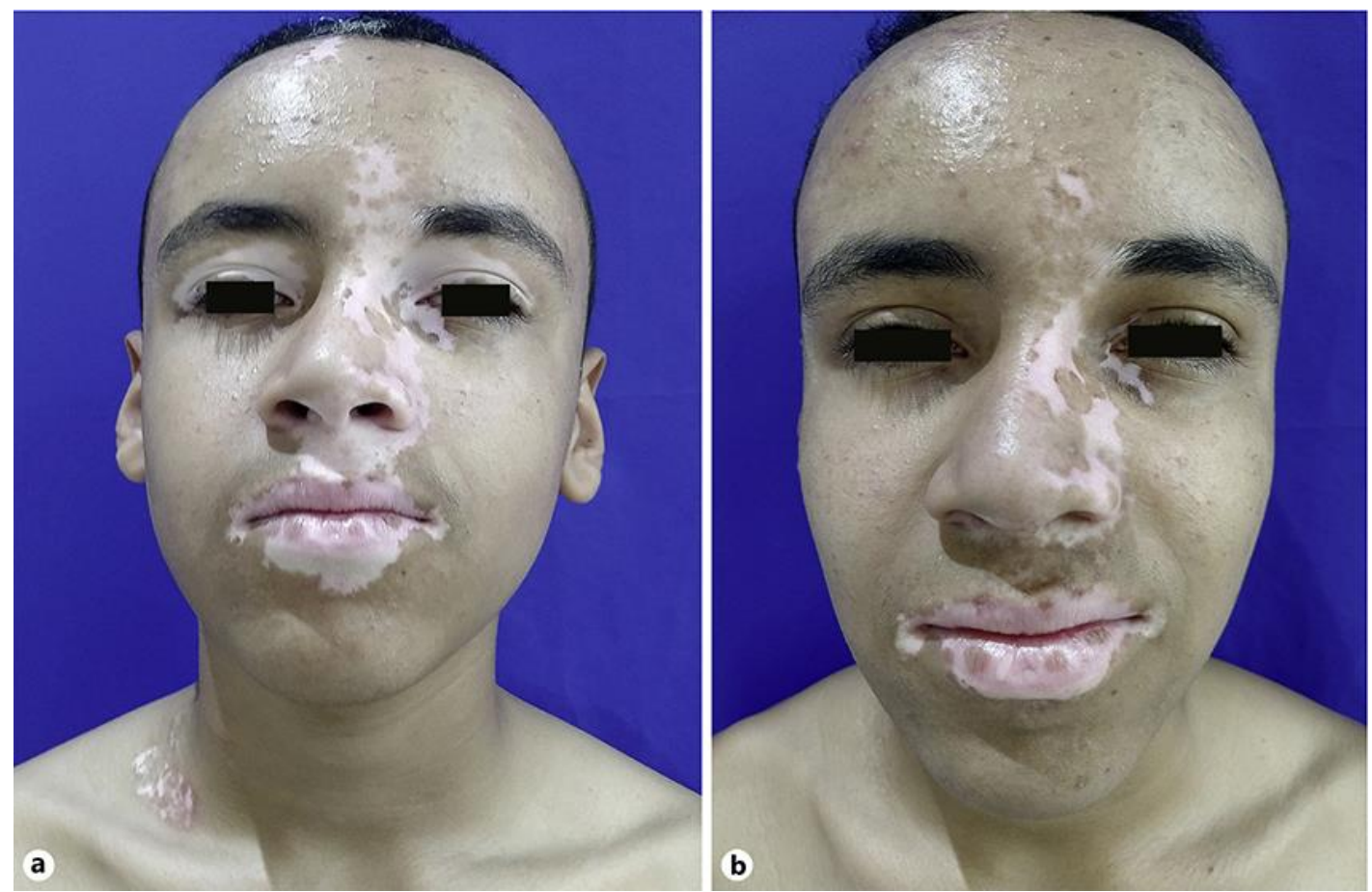

Fig. 1. a At baseline, the 17-year-old boy had an evident and continuous white macule along his forehead, right and left periorbital region, nose, and lips, as well as a single macule right above his right clavicle. $\mathbf{b}$ After 9 months of therapy, repigmentation was near complete in both periorbital regions, around his lips, and above his clavicle, besides great improvement in the nasal area.

\section{Karger'}




\section{Case Reports in Dermatology}

(C) 2021 The Author(s). Published by S. Karger AG, Basel

Berbert Ferreira et al.: Topical Tofacitinib for the Treatment of Vitiligo in an Adolescent

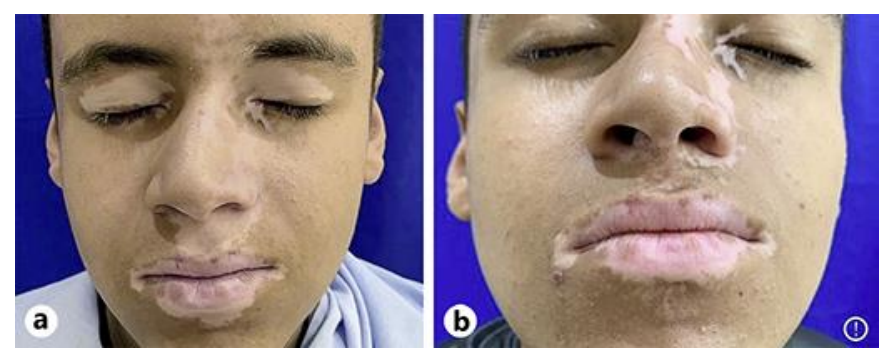

Fig. 2. a At baseline. Details of the continuous white macule around the patient's lips and periorbital region. b After 9 months of therapy, there was considerable repigmentation around the patient's lips and periorbital region compared to a. 